\title{
VALIDATION OF NEW MULTI-RESIDUE METHOD FOR THE DETERMINATION OF ORGANOPHOSPHORUS INSECTICIDES IN CHRYSANTHEMUM FLOWER BY CAPILLARY GAS CHROMATOGRAPHY Awadh, G. ${ }^{1}$ and D. S. Zhao ${ }^{2}$. \\ 1- Plant Protection Dept., Fac. of Agric., Sana'a Univ., Sana'a, Yemen \\ 2- Central Laboratory, Zhejiang Univ., Hangzhou, China
}

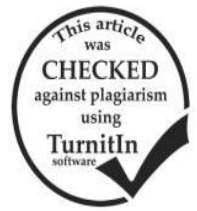

\begin{abstract}
A method for the analysis of 8 organophosphorus (OP) with wide range of physico-chemical properties in Chrysanthemum flower was developed and validated. The procedure involved the extraction of the spiked sample $(5 \mathrm{~g})$ with 100 $\mathrm{mL}$ acetone and the final volume was not subjected to any clean-up procedure. The analyte concentrations were determined through gas chromatography GC-9A, equipped with flame photometric detector (FPD). The mean recoveries of the spiked blank samples at three concentrations for different pesticides were found in the range of 91.00-99.67\% and relative standard deviation lower than $12.0 \%$. Limit of detection (LOD) of the method ranged between 0.06 and $0.08 \mathrm{mg} \mathrm{kg}^{-1}$ and the limit of quantitation (LOQ) were varied from 0.09 to $0.1 \mathrm{mg} \mathrm{kg}^{-1}$. The selected parameters for method validation (precision, accuracy, calibration function, sensitivity, selectivity, limit of detection and limit of quantitation) were within the acceptable limits according to the EU criteria (SANCO) for the 8 insecticides included in the validation.
\end{abstract}

Keywords: Chrysanthemum flower; Multi-residue analysis; gas chromatography; validation

\section{INTRODUCTION}

Medicinal plants have been used therapeutically all around the world, being an important aspect of various traditional medicine systems. During the past few decades, phytotherapy has started to be increasingly used even in industrialized countries. In low and middleincome countries, phytotherapy never stopped being important, often representing the only therapeutic system to which certain people could refer. With the everincreasing use of herbal medicines worldwide and the rapid expansion of the global market for these products, the safety and quality of medicinal plant materials and finished herbal medicinal products have become a major concern for health authorities, pharmaceutical industries and the public. Contaminants in herbal medicines are classified into physicochemical contaminants and biological contaminants. A variety of agrochemical agents and some organic solvents may be important residues in herbal medicines.(WHO guidelines 2007). However, pesticides are often used in order to improve productivity and profit margins in the production of Chinese medicinal materials. The published researches on pesticide residues in crude herbal materials indicate that the presence of organophosphorus pesticide (OPP) residues is quite common (Ozbey and Uygun 2007; Vidal et al. 2002; Garrido-Frenich et al. 2003). Hence pesticide residues in Chinese medicinal materials become pitfalls in safety and present obstacles to be acknowledged by the international community (Qing et al. 2009). In recent years, with the significant improvements in pesticide analytical techniques and tremendous concerns in the safety of consumers' products, the pesticides residues in foods have been more strictly monitored, the respective analytical methods of 3 pyrethroids and 12 organophosphorous (OPs) pesticides, but no MRLs for pyrethroids and organophosphorous pesticides (OPPs) have been established for all Chinese medicinal materials, (China Pharmacopoeia 2005). Among several Medicinal plants, Chrysanthemum flower (Pharmaceutical Name:
Flos Chrysanthemi, Botanical Name: Chrysanthemum morifolium Ramat. Common Name: Chrysanthemum flower) is one of the most popular Chinese herbal medicines. Chrysanthemums not only are these flowers beautiful additions to gardens and homes but they have also shown to reduce indoor air pollution and also have medicinal properties, it can be used to treat western symptoms such as: irritability, thirst, cough-phlegm, cough-blood, carbuncles, sores and breast-lumps and Chinese symptoms such as: lung-heat, lung-phlegm heat, yin-deficient and fire poison. Although Chrysanthemums produce their own natural insecticide they still have a plethora of pests that can attack them and cause leaves and petals to wilt, and sometimes even kill the entire plant. Invertebrates such as nematodes, leaf roller, thrips, aphids, mites, caterpillars, weevils and flies are most common (Williams and Pullman 2000; Sabir et al. 2012). Chrysanthemums usually attacked by a variety of chewing, sucking and rasping (scraping) pests, the most common insect pests of Chrysanthemum are Chewing insects: $\quad$ Budworms (Helicoverpa spp.), Cineraria leafminer (Chromatomyia syngenesiae), Chrysanthemum Leafminer (Phytomyza syngenesiae), Chrysanthemum gall midge (Rhopalomyia chrysanthemi) and European earwigs (Forficula auricularia); Sucking insects: Chrysanthemum aphids (Macrosiphoniella sanborni), Broad mite (Polyphagotarsonemus latus), Cyclamen mite (Phytonemus pallidus), Two-Spotted Spider Mites (Tetranychus urtica); Rasping insects: Western Flower Thrips (Frankliniella occidentalis) (Marjan et al. 2006). Late season infestations of pest populations on Chrysanthemums can cause severe damage and reduced flower quality, therefore the application of organophosphorus pesticides is became necessary to reduce the damage and to improve the flower quality and this may lead to some residues on the flower. To be able to detect such residues, we have to develop a valid, simple, reliable, rapid, efficient method. Method validation is an important requirement in the practice of chemical analysis. The analyst must generate information to show that a method intended for these 
purposes is capable of providing adequate specificity, accuracy and precision, at relevant analyte concentrations and in appropriate matrices (Hill and Reynolds 1999). Most of pesticide residue methods are carried out with modern, sophisticated and expensive instruments (GC/MS, LC/MS), such kind of instruments are rarely found and usually not available in each pesticide residue laboratories, especially in the developing countries. In the literature, no method was found to determine the residues of organophosphorus insecticides in Chrysanthemum flower, therefore, the present study deals with developing a rapid and efficient multiresidue analytical method for the determination of 8 insecticides in Chrysanthemum flower using common gas chromatography equipped with flame photometric detector (FPD).

\section{MATERIALS AND METHODS}

\section{Sample Preparation}

All crops were purchased at a local market in Hangzhou (China) and we confirmed that the concentrations of pesticide residues in foods were below detectable levels with the proposed method. About 500 $\mathrm{g}$ of food was chopped in a DC- 200 high speed blender (Shanghai, China) for 2 min to obtain thoroughly mixed homogenates. Wide range of physico-chemical properties of representative insecticides were selected to assess the laboratory performance of the method, (Table 1).

Table 1. Summary of physico-chemical properties of selected representative insecticides

\begin{tabular}{|l|c|c|c|c|c|c|c|}
\hline \multirow{2}{*}{$\begin{array}{l}\text { Active } \\
\text { ingredient }\end{array}$} & \multicolumn{2}{|c|}{ Water solubility } & \multicolumn{2}{c|}{$\log$ Pow } & \multicolumn{2}{|c|}{ Vapour pressure } & Hydrolysis (pH 9) \\
\cline { 2 - 7 } & $\mathbf{m g} / \mathbf{l}$ & ${ }^{\mathbf{0}} \mathbf{C}$ & & ${ }^{\mathbf{0}} \mathbf{C}$ & $\mathbf{~} \mathbf{P a}$ & ${ }^{\mathbf{0}} \mathbf{C}$ & $\mathbf{h a l f}-$ life \\
\hline Dimethoate & 23.3 & 20 & 0.704 & 20 & 1.10 & 25 & $12 \mathrm{~d}$ \\
\hline Malathion & 145 & 25 & 2.7 & 25 & 5.30 & 30 & $11.8 \mathrm{~h}$ \\
\hline Methamidophos & 200 & 20 & -0.8 & 20 & 2.30 & 20 & $120 \mathrm{~h}$ \\
\hline Omethoate & 39.8 & 25 & -0.74 & 20 & 3.30 & 20 & $4.4 \mathrm{~d}$ \\
\hline Parathion & $55-60$ & 25 & 3.43 & 20 & 1.30 & 20 & $100 \mathrm{~d}$ \\
\hline Parathion - methyl & 70 & 25 & 2.8 & 25 & 1.30 & 20 & $33 \mathrm{~d}$ \\
\hline Phosmet & 25 & 25 & 2.95 & 20 & 0.065 & 25 & $0.02 \mathrm{~d}$ \\
\hline Trichlorphon & 120 & 20 & 0.43 & 20 & 0.21 & 20 & $0.5 \mathrm{~h}$ \\
\hline
\end{tabular}

The standard pesticides were obtained from Sigma-Aldrich (Germany) with purity more than $96 \%$. The stock and working solutions were prepared in pesticide residue grade acetone solvent, obtained from Lian You factory (Hangzhou, China).

\section{Extraction}

An aliquot of $5 \mathrm{~g}$ of sample homogenate was weighed into a high speed blender jar Model DC- 200 model tool factory (Shanghai, China) and the fortification standard was added into the sample and allowed to equilibrate for $12 \mathrm{~h}$ before extraction. The spiked sample was extracted with a $100 \mathrm{ml}$ of acetone for $2 \mathrm{~min}$. The extract was transferred into $250 \mathrm{~mL}$ conical flask, and the blender jar was washed three times with $100 \mathrm{~mL}$ acetone into the same conical flask and shacked with a mechanical shaker model Haake SWB20 (Germany) for 30 mintues. The extract was filtered through glass funnel containing anhydrous sodium sulfate (analytical grade) obtained from Lan qi reagents and chemical factory (China) and the filtrate was collected into $250 \mathrm{~mL}$ round bottom flask. the conical flask washed with $100 \mathrm{~mL}$ acetone in three portions and added to the filtrate. The filtrates and washing solutions were combined before being concentrated to ca $2 \mathrm{~mL}$ with rotary vacuum evaporator model SBXZ (Shanghai, China) at $40{ }^{\circ} \mathrm{C}$. The final volume of the extract was adjusted to $10.0 \mathrm{~mL}$ test tube with acetone and was not subjected to any clean-up procedure, the final volume analyzed was $1 \mu \mathrm{L}$. The analyte concentrations were determined through gas chromatography GC-9A, equipped with FPD detector connected to a C-R3A reporting integrator from
Shimadzu Corp. (Kyoto, Japan) and a 30-m AT-1701 (Altech) capillary column, with an internal diameter of $0.53 \mathrm{~mm}$ and film thickness of $1.2 \mu \mathrm{m}$. The analytical conditions were injector temperature: $250^{\circ} \mathrm{C}$, the carrier gas $\left(\mathrm{N}_{2}\right)$ with a flow rate of $35 \mathrm{~mL} \mathrm{~min}^{-1}$. Hydrogen and air was used as a detector gases with flow rate of 90 and $500 \mathrm{~mL} \mathrm{~min}^{-1}$ respectively. The detector temperature set at: $275^{\circ} \mathrm{C}$, and the injections were done in the oncolumn injection mode with an oven temperature program of $120^{\circ} \mathrm{C}$ for $1 \mathrm{~min}, 20^{\circ} \mathrm{C} \mathrm{min}{ }^{-1}-180^{\circ} \mathrm{C}$, and $40{ }^{\circ} \mathrm{C} \min ^{-1}-250{ }^{\circ} \mathrm{C}$ for $2 \mathrm{~min}$. Recoveries were determined by adding the tested pesticides to a control Chrysanthemum sample and the pesticide residues were calculated by external standard method. Analytical validation of the method was performed to check the credibility of the data in the quantitative analyses by applying the flowing factors: recovery, accuracy, precision, determination coefficient $\left(\mathrm{R}^{2}\right)$, detection (LOD) and quantification (LOQ) limits (Hill and Reynolds 1999; Aysal et al. 2007). The selected parameters for method validation for the analysis of pesticide residues in herbal products were mainly taken from the European Directorate General for Health and Consumer Affairs (SANCO/12495/2011).

\section{RESULTS AND DISCUSSION}

\section{Selection of representative analytes}

In order to develop a universal analytical method and to assess the laboratory performance of the method, representative insecticides (different polarities, solubilities, volatilities and $\mathrm{pKa}$ values) that have to be 
simultaneously extracted and analysed should be selected (FAO/WHO) 2003; Alder et al. 2006) Table 1 demonstrates the physico-chemical properties of the selected representative compounds with wide range of properties: water solubility from 23.3 to $200 \mathrm{mg} / \mathrm{l}$; logPow: from -0.8 to 3.43 ; vapour pressure: from 0.065 to $5.30 \mathrm{mPa}$; and hydrolytic stability from 0.02 to 100 days at $\mathrm{pH} 9$ were selected.

\section{Pesticide extraction from samples}

A number of solvents have been used for multiresidue extractions and the most common include acetone (P. Van Zoonen 1996; Hans-J SJ 2000) ethyl acetate (Hernando et al. 2001; Berrada et al. 2006; Georgakopoulos et al. 2007) and acetonitrile (Lee et al. 1991; Fillion et al. 2000; Anastassiades et al. 2003). Acetone was selected as the solvent for extraction of pesticides because of its effectiveness for very polar insecticides ( $\operatorname{logKow}<0$, methamidophos, omethoate), polar and nonpolar pesticides from a diverse range of matrices. Its other advantages include low toxicity and cost, miscibility with water and ease of evaporation.

\section{Clean up}

Inadequate or extensive clean-up of extracts may result in the partial loss of some compounds as well as increased labour, cost demands and can lead to adverse effects related to the quality of the generated data (Darinka et al. 2003). In this experiment, the selective detector (FPD) was used for the determination of the residues, we found that clean up was not necessary to perform the method. Interference from co-extractives was not found to interfere with the tested pesticides (Figure 1).

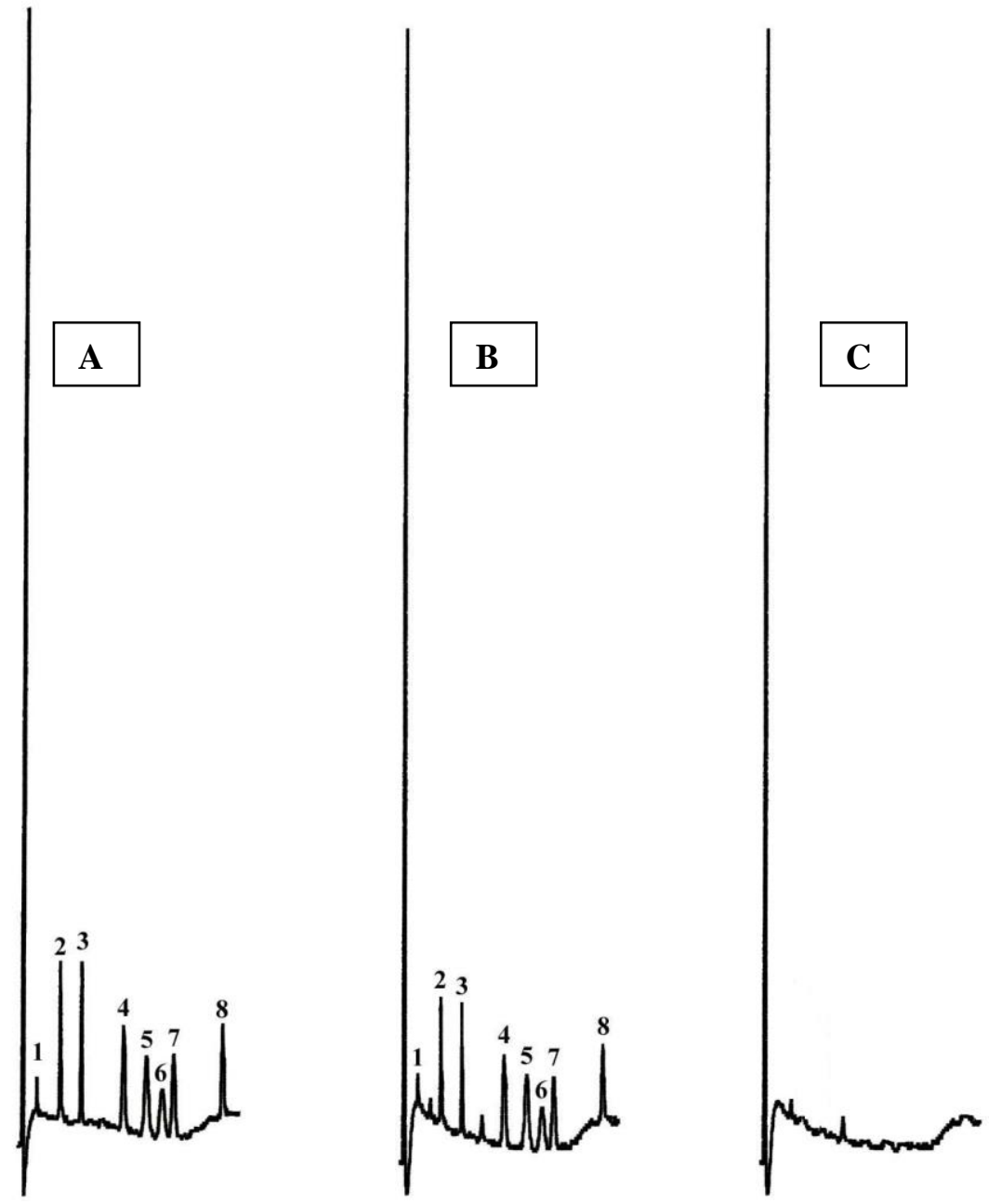

Figure 1. Representative gas chromatograms of (A) Insecticide standards (B), Chrysanthemum sample fortified with OP insecticide $0.1 \mathrm{mg} \mathrm{kg}^{-1}$. Peak identities are Omethoate (1), Methamidophos (2), Trichlorphon (3), Dimethoate (4). Parathion methyl (5), Malathion (6), Parathion (7), Phosmet (8). (C) Control Chrysanthemum.

\section{Method validation}

Validation is performed to verify that the method is fit for purpose, which means that the desired commodities and analytes are evaluated to achieve acceptable recoveries, reproducibilities, and detection limits. Sample preparation was rapid and straightforward. Cost and waste, consumption of solvents and reagents was low, that is with agreement with EU directives with regard to sample definition (Annex I to Directive 90/642/EEC 1993) and laboratory 
sample size (Commission directive 2002) for residue analysis should be respected. In order to prevent the degradation of the analytes, samples were extracted by blending for 2 minutes only before shaking, It has been reported that for well homogenized samples extraction by vortex mixing or shaking, instead of high-speed blending (Turrax) suffices for effective extraction (Anastassiades et al. 2003).

Table 2. Recovery (\%) and reproducibility $(\mathrm{CV} \%)$ of the for 8 representative insecticides at different spiking levels $(\mathbf{n}=9)$.

\begin{tabular}{|c|c|c|c|c|c|c|c|c|c|}
\hline \multirow{2}{*}{ Insecticide } & \multirow{2}{*}{$\begin{array}{c}\text { Fortification } \\
\left(\mathrm{mg} \mathrm{kg}^{-1}\right)\end{array}$} & \multicolumn{2}{|c|}{ Batch 1} & \multicolumn{2}{|c|}{ Batch 2} & \multicolumn{2}{|c|}{ Batch 3} & \multicolumn{2}{|c|}{ Overall } \\
\hline & & mean & $\% \mathrm{CV}$ & mean & $\% \mathrm{CV}$ & mean & $\% \mathrm{CV}$ & mean & $\% \mathrm{CV}$ \\
\hline \multirow{3}{*}{ Dimethoate } & 2.00 & 94 & 10 & 89 & 2 & 88 & 3 & 91 & 5 \\
\hline & 0.20 & 93 & 11 & 92 & 10 & 92 & 9 & 92 & 10 \\
\hline & 0.10 & 104 & 8 & 90 & 3 & 110 & 4 & 101 & 10 \\
\hline \multirow{3}{*}{ Malathion } & 2.36 & 86 & 4 & 86 & 5 & 85 & 6 & 86 & 5 \\
\hline & 0.24 & 106 & 9 & 105 & 12 & 105 & 11 & 106 & 10 \\
\hline & 0.12 & 83 & 4 & 100 & 4 & 102 & 10 & 95 & 11 \\
\hline \multirow{3}{*}{ Methamidophos } & 1.19 & 108 & 12 & 101 & 11 & 113 & 9 & 107 & 11 \\
\hline & 0.12 & 99 & 17 & 98 & 9 & 102 & 12 & 100 & 13 \\
\hline & 0.06 & 83 & 6 & 103 & 13 & 92 & 10 & 92 & 11 \\
\hline \multirow{3}{*}{ Omethoate } & 2.21 & 94 & 9 & 86 & 9 & 97 & 9 & 92 & 9 \\
\hline & 0.22 & 100 & 10 & 100 & 11 & 108 & 6 & 103 & 9 \\
\hline & 0.11 & 81 & 9 & 98 & 6 & 82 & 8 & 87 & 11 \\
\hline \multirow{3}{*}{ Parathion } & 1.89 & 89 & 14 & 86 & 9 & 85 & 10 & 86 & 11 \\
\hline & 0.19 & 99 & 10 & 101 & 14 & 101 & 6 & 100 & 10 \\
\hline & 0.10 & 77 & 5 & 94 & 12 & 89 & 10 & 87 & 10 \\
\hline \multirow{3}{*}{ Parathion- methyl } & 2.14 & 86 & 6 & 92 & 13 & 84 & 7 & 87 & 9 \\
\hline & 0.21 & 98 & 12 & 110 & 11 & 100 & 13 & 103 & 12 \\
\hline & 0.11 & 99 & 6 & 83 & 12 & 83 & 6 & 88 & 10 \\
\hline \multirow{3}{*}{ Phosmet } & 2.26 & 98 & 8 & 97 & 10 & 95 & 12 & 97 & 10 \\
\hline & 0.23 & 103 & 10 & 103 & 11 & 102 & 7 & 103 & 10 \\
\hline & 0.12 & 85 & 5 & 105 & 10 & 87 & 5 & 92 & 12 \\
\hline \multirow{3}{*}{ Trichlorphon } & 3.28 & 100 & 9 & 101 & 9 & 107 & 9 & 103 & 9 \\
\hline & 0.33 & 104 & 7 & 103 & 13 & 93 & 14 & 100 & 11 \\
\hline & 0.17 & 79 & 7 & 85 & 9 & 97 & 7 & 87 & 11 \\
\hline
\end{tabular}

\section{Precision}

Recovery data from the fortified controls was used to measure repeatability and reproducibility variation of the method at $0.1-2 \mathrm{mg} \mathrm{kg}^{-1}$ and expressed as \% CV. Each analytical batch comprised of 10 negative control samples, and the test was repeated on three occasions at each concentration. All the recoveries obtained were within the acceptable range (70-120) see Table 2.

Accuracy

Accuracy was described as the overall recovery (table 2), it is the mean recovery obtained for each compound, at each fortification level, for all observations.

\section{Calibration and matrix function}

Organophosphorus insecticide standard solutions ( 0.1 to $2 \mathrm{mg} \mathrm{kg}^{-1}$ ) were prepared in acetone and assayed on three separate occasions. Standard curves were

\section{Recovery test}

Recovery experiments using spiked blank samples at three concentrations showed that mean recoveries for different pesticides were found in the range of 91.00-99.67\% and relative standard deviation (RSD) were all lower than $12.0 \%$ (Table 2), the results met the EU criteria (recovery $70-120 \%$, RSD $\leq 20 \%$ (SANCO 2011) for the 8 insecticides included in the validation. 
Table 3. t-test, Mean Values of Slope, Intercept and Regression Coefficient $\left(r^{2}\right)$ for Organophosphorus Insecticides In Standard Solutions and Matrix

\begin{tabular}{|l|c|c|c|c|c|c|c|c|}
\hline \multirow{2}{*}{ Insecticide } & \multicolumn{2}{|c|}{ Slop } & \multicolumn{2}{c|}{ Intercept } & \multicolumn{2}{c|}{$\mathbf{R}^{2}$} & \multicolumn{2}{c|}{ t-test } \\
\cline { 2 - 9 } & Std & Matrix & Std & Matrix & Std & Matrix & tcalc & t-critical \\
\hline Omethoate & 0.965 & 0.956 & 0.639 & 18.314 & 0.992 & 0.993 & 1.8898 & 4.303 \\
\hline Methamidophos & 7.238 & 7.268 & 2.406 & 2.503 & 0.993 & 0.994 & 1.3093 & 4.303 \\
\hline Trichlorphon & 1.977 & 1.977 & 2.564 & 2.864 & 0.991 & 0.990 & 2.5000 & 4.303 \\
\hline Dimethoate & 2.496 & 2.496 & 1.687 & 1.887 & 0.991 & 0.993 & 4.000 & 4.303 \\
\hline Parathion & 1.874 & 1.882 & 1.228 & 1.510 & 0.993 & 0.994 & 0.2500 & 4.303 \\
\hline parathion-methyl & 0.967 & 0.941 & 0.763 & 1.084 & 0.996 & 0.997 & 2.0000 & 4.303 \\
\hline Phosmet & 1.513 & 1.490 & 1.383 & 1.704 & 0.994 & 0.994 & 1.7321 & 4.303 \\
\hline Trichlorphon & 1.061 & 1.066 & 1.497 & 1.813 & 0.991 & 0.990 & 0.6547 & 4.303 \\
\hline
\end{tabular}

\section{Sensitivity}

Slope, intercept and correlation coefficient $\left(\mathrm{r}^{2}\right)$ was used to express the sensitivity of the method, for each compound, over the range 0.1 to $2 \mathrm{mg} \mathrm{kg}^{-1}$ (Table 3). All the results obtained were within the acceptable limits.

\section{Selectivity}

Peak retention time was used to determine the selectivity of the method, no interference from coextractives was found to interfere with the tested pesticide, good resolution was obtained by the method; (figure 1). Dual column confirmation was used, pesticides eluted with different retention times on 2 different column phases, but retention times remain constant from both columns (Mid-polar AT-1701 capillary column (Altech), 30m, $0.53 \mathrm{~mm}$ id, $1.2 \mu \mathrm{m}$ and
Non-polar HP-5 capillary column (Agilent) 30m, $0.32 \mathrm{~mm}$ id, $0.25 \mu \mathrm{m}$ film thickness. 1 = Omethoate, $2=$ methamidophos, $3=$ trichlorphon , $4=$ dimethoate, $5=$ parathion-methyl, $6=$ malathion, $7=$ parathion, $8=$ phosmet (Table 4).

\section{Limit of Detection (LOD) and Limit of Quantitation (LOQ):}

The limits of detection (LOD) and quantification (LOQ) for all pesticides were calculated by considering a value 3 and 10 times the background noise obtained for blank samples, respectively. LOD and LOQ for all OP insecticides at $0.1 \mathrm{mg} \mathrm{kg}^{-1}$ are shown in Table 4 . LODs of the method ranged between $0.06 \mathrm{mg} \mathrm{kg}^{-1}$ for Parathion and $0.08 \mathrm{mg} \mathrm{kg}^{-1}$ for Phosmet, LOQs were varied from 0.09 to $0.1 \mathrm{mg} \mathrm{kg}^{-1}$ for various analytes studied.

Table 4. Method Detection Limit (MDL) and Limit of Quantitation of OPs Insecticide on Gas Chromatograph by FPD.

\begin{tabular}{|c|c|c|c|}
\hline Name & $\begin{array}{c}\text { Retention } \\
\text { Time }\end{array}$ & $\begin{array}{l}\text { Method Detection Limit } \\
(\mathrm{MDL})\left(\mathrm{mg} \mathrm{kg}^{-1}\right)\end{array}$ & $\begin{array}{c}\text { Limit of Quantification (LOQ) } \\
\left(\mathrm{mg} \mathrm{kg}^{-1}\right)\end{array}$ \\
\hline Omethoate & 1.03 & 0.07 & 0.09 \\
\hline Methamidophos & 2.24 & 0.07 & 0.10 \\
\hline Trichlorphon & 3.38 & 0.06 & 0.09 \\
\hline Dimethoate & 5.63 & 0.07 & 0.10 \\
\hline Parathion - methyl & 6.86 & 0.06 & 0.09 \\
\hline Malathion & 7.70 & 0.07 & 0.10 \\
\hline Parathion & 8.30 & 0.06 & 0.09 \\
\hline Phosmet & 11.09 & 0.08 & 0.11 \\
\hline
\end{tabular}

\section{CONCLUSIONS}

The present multi-residue method, developed for the simultaneous determination of 8 insecticides in Chrysanthemum flower involves a rapid extraction procedure and a specific GC-FPD determination with satisfactory recoveries and LODs. The method described in this study has shown suitable sensitivity for monitoring a wide range of pesticide residues in Chrysanthemum flower.

\section{REFERENCES}

Alder L, Greulich K, Kempe G, and Vieth B (2006) Residue analysis of 500 high priority pesticides: better by GC-MS or LC-MS. MassSpectrom Rev 25(6):838-865
Anastassiades M, Lehotay S, Štajnbaher D, and Schenck F (2003) Fast and easy multiresidue method employing acetonitrile extraction/partitioning and "dispersive solid-phase extraction" for the determination of pesticide residues in produc. Assoc. Off. Anal. Chem 86(20):412-431

Anastassiades M, Lehotay SJ, Stajnbaher D, and Schenk FJ (2003) J Assoc Off Anal Chem 86:412-431

Annex I to Directive 90/642/EEC [Part of products to which maximum limits apply], as amended by Directive 93/58/EEC (OJL 211, 23.8.1993, p. 6)

Aysal P, Ambrus A, Lehotay S, and Cannavan A (2007) Validation of an efficient method for the determination of pesticide residues in fruits and vegetables using ethyl acetate for extraction. J Environ Sci Health, Part B 42:481-490 
Berrada H, Fernández M, Ruiz MJ, Moltó JC, and Mañes J (2006) Exposure assessment of fruits contaminated with pesticide residues from Valencia, 2001-03, Food Additives and Contaminants. 23(7):674-682

China Pharmacopoeia (2005) Chinese Pharmacopoeia of People's Republic of China. Chemical Industry Press, Beijing. Section [Z]. 2005: appendix 52.

Commission directive 2002/63/EC of 11 July 2002 establishing Community methods of sampling for the official control of pesticide residues in and on products of plant and animal origin and repealing Directive 79/700/EEC, Official Journal of the European Communities L187, 16/07/2002, P. 30-43

Darinka S, Lucija Zupan C, and Kralj b (2003) Multiresidue method for determination of 90 pesticides in fresh fruits and vegetables using solid-phase extraction and gas chromatographymass spectrometry. J Chromatogr A, 1015:185198

Fillion J, Sauvé F, and Selwyn J (2000) Multiresidue method for the determination of residues of 251 pesticides in fruits and vegetables by gas chromatography/mass spectrometry and liquid chromatography with fluorescence detection. J. Assoc. Off. Anal. Chem. 83:698-713

Food and Agriculture Organization/World Health Organization (FAO/WHO) (2003) Guidelines on Good Laboratory Practice in Residue Analysis, CAC/GL 40-1993; Rome, Italy

Garrido-Frenich A, Arrebola FJ, Gonz'alez-Rodr'1guez MJ, Vidal JLM, and D'iez NM (2003) Rapid pesticide analysis, in post-harvest plants used as animal feed, by low-pressure gas chromatography-tandem mass spectrometry. Anal Bioanal Chem 377(6)1038-1046

Georgakopoulos P, Foteinopoulou E, Athanasopoulos P, Drosinos E, and Skandamis P (2007) Recoveries of four representative organophosphorus pesticides from 18 plant products belonging to different botanical categories: Implications for matrix effects, Food Additives and Contaminants. 24(4): 360-368.

Hans-J SJ (2000) Pesticide residue analysis in foodstuffs applying capillary gas chromatography with mass spectrometric detection State-of-theart use of modified DFG-multimethod S19 and automated data evaluation. Chromatogr. A 892:347-377
Hernando M.D, Agüera A, Fernández-Alba A.R, Piedra L, and Contreras M, (2001) Gas chromatographic determination of pesticides in vegetable samples by sequential positive and negative chemical ionization and tandem mass spectrometric fragmentation using an ion trap analyser. Analyst 126:46-51

Hill A, and Reynolds S (1999) Guideline for in-house validation of analytical methods for pesticide residues in food and animal feeds. Analyst 124:953-958

Lee SM, Michael LP, Hsiao-Ming CF, Hunter GF, and Carr JE (1991) Multipesticide residue method for fruits and vegetables: California Department of Food and Agriculture. Fr. J. Anal. Chem. 339:376-383

Marjan K, McLeod S, James H, and Clyde S, (2006) Chrysanthemum Diseases \& Insect Pests. http://www.clemson.edu/extension/hgic/pests/pdf /hgic2101.pdf

Ozbey A, and Uygun U, (2007) Behaviour of some organophosphorus pesticide residues in thyme and stinging nettle tea during infusion process. Int J Food Sci Tchnol, 42(3):80-383

P. Van Zoonen (Ed.), Analytical methods for pesticide residues in foodstuff, $6^{\text {th }}$ ed., general inspectorate for health protection, ministry of health, welfare and sport, Amsterdam, the Netherlands, 1996

Qing G, Xia L, Li T, and Bo-Yang Y (2009) Simultaneous determination of 26 pesticide residues in 5 Chinese medicinal materials using solid-phase extraction and GC-ECD method. Chin J of Nat Med 7(3):210-216.

Sabir N, Deka S, Tanwar R, Singh B, Raj S, Adhikari S, Sindhu S (2012) Comparative evaluation of pesticides and biorationals against key pests of greenhouse chrysanthemum. Indian $\mathrm{J}$ Hortic 69(1):101-105

SANCO/12495/2011, Method Validation and Quality Control Procedures for Pesticide Residue Analysis in Food and Feed, Implemented by 01/01/2012.

Vidal J, Arrebola FJ, Mateu-S'anchez, (2002) Multiresidue method for determination of pesticides in vegetable samples by GC-MS-MS. Chromatogr 56(7-8)475-481

Williams D, Pullman K, (2000) Pests of Chrysanthemums.http://www.dpi.vic.gov.au/agri culture/pests-diseases-and-weeds/pestinsects/pests-of-chrysanthemums

World Health Orgnization (WHO) (2007) Guidelines for assessing quality of herbal medicines with reference to contaminants and residues, World HealthOrganization.ww.who.int/medicinedocs/in dex/assoc/s14878e/s14878e.pdf 
التثبت من (اختبار فاعلية) طريقة جديدة للمتبقيات العديدة لتقدير المبيدات الفسفورية العضوية الحشرية في زهرة

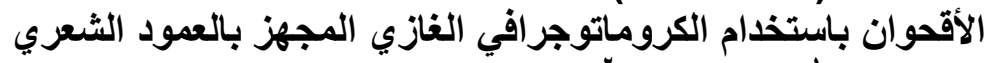

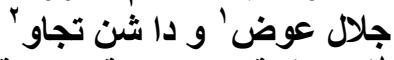

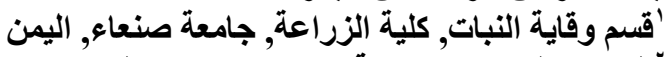

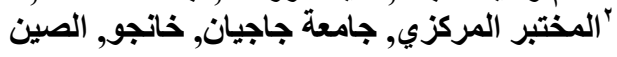

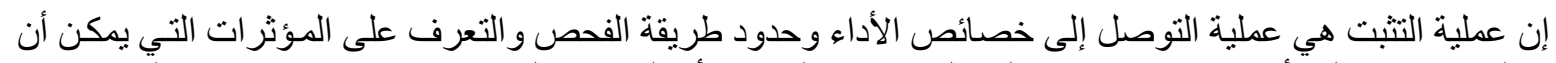

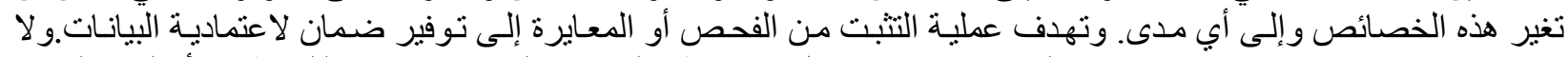

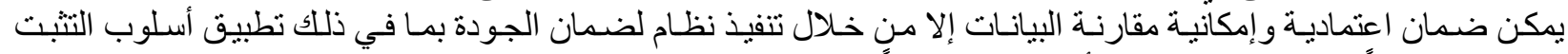

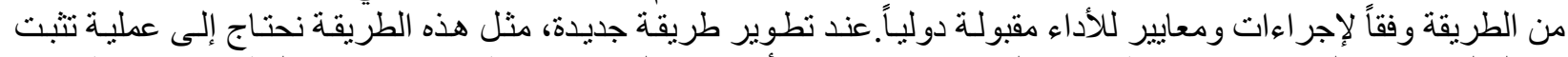

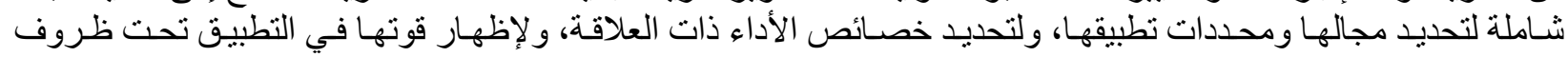

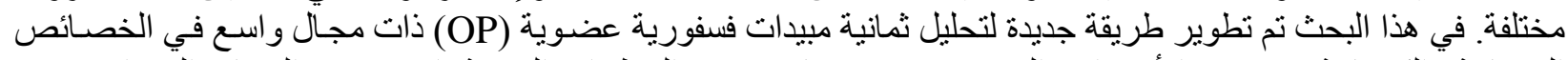

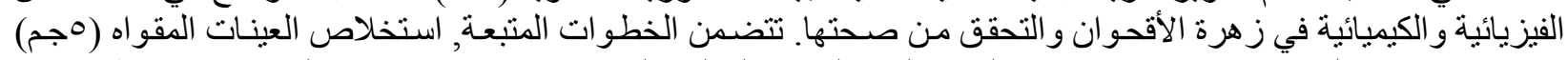

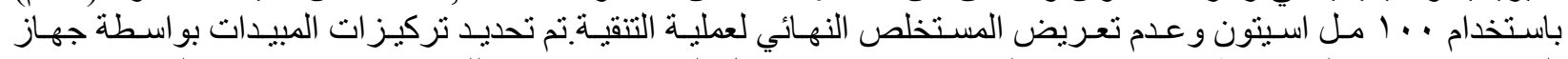

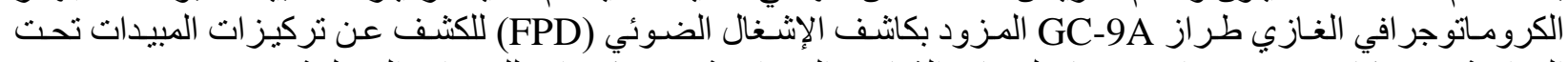

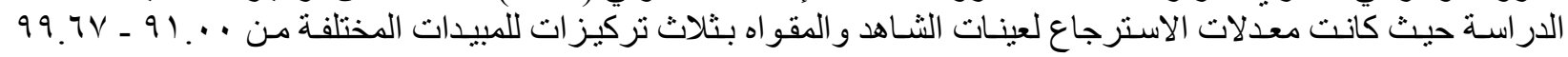

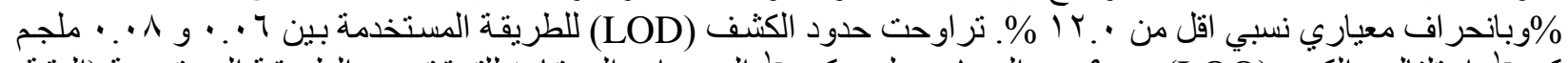

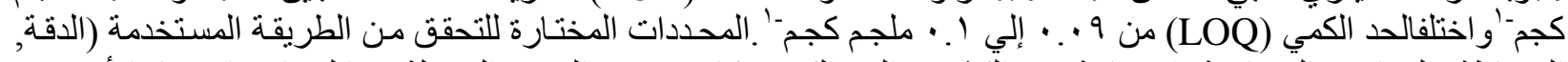

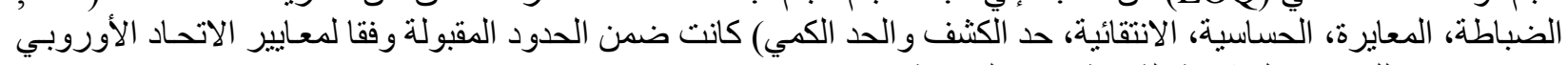
للمبيدات الحشرية الثمانية تحت الدرائة الكية. 